\title{
Transformation model and innovation research on tech- nological achievements of silk industry
}

\author{
Honggen Yi \\ National Engineering Laboratory for Modern Silk, Soochow University, Suzhou, China
}

\begin{abstract}
On Base of analysis about the present situation of scientific and technological achievements transformation in silk industry, the paper aimed to innovate the transformation modes of scientific and technological achievements in our silk industry, and increase the achievements transformation efficiency, expecting to promote our country developed into "silk power".
\end{abstract}

Keywords: Silk industry; Transformation mode; Scientific and technological achievement; Mechanism innovation.

\section{Introduction}

Technological innovation was placed at the core of overall national development on the Eighteenth National Congress and the Third Plenary Session of Communist Party of China. It has always been the crucial component of national strategy. The Premier of the State Council, Li Keqiang, pointed out that technological achievements should be transformed into actual productivity to serve the national strategy and to benefit the people ${ }^{[1]}$. The transformation of scientific and technological achievements, which is the key part in speeding up the economy, is an important symbol of technological development of a country or a region. Considering the development status of technology and its role in productivity, the transformation of scientific and technological achievements into real productivity should be promoted vigorously.

2. Analysis of the status of transformation of scientific and technological achievements in silk industry

Silk has both cultural and economic attributes; it is a combination of profound history and modern technology. Chinese silk can be dated back to more than 7000 years ago, and it is a specialty industry with strong international competitiveness. At present, twenty million peasant households are engaged in silk industry, including nearly sixty million farmers. The number of people related to the production and circulation of silk industry is more than two million. Therefore, the healthy development of silk industry has a great bearing on supporting "three principles of nationalism, democracy and people's livelihoods". Though as a country with large silk industries, China has a long way to go to become a powerful one. The capabil- ity of independent innovation needs to be enhanced urgently.

Currently, reasons for the scarcity of high-innovation and high-maturity achievements and deficiency of transformation are listed as follows.

\subsection{Shortage of advanced talents and training chan- nels.}

In the 1990s, Ministry of Education adjusted the catalogue of majors for recruiting undergraduate students, with the deletion of the major of silk engineering and the addition of textile engineering as a large major. This led to reduced training for advanced talents and deficiency of teachers in silk-related teaching or scientific research. As a result, there are fewer staff to engaged in technological innovation in silk industry and the talent structure is unreasonable. The high speed of national silk industry expansion does not coordinate with the cultivation speed of its technological talents, especially after the national strategy of transferring mulberry silkworm raising industry from the east to the west.

\subsection{The influence of high-tech evaluation system.}

As universities adopt the evaluation system for science and technology achievements, the scientific research by teachers in silk teaching does not coordinate with the market. The emphasis is given to theoretical research rather than practical teaching, and academic papers are more valued than actual research and development of technology. Some researcher have not get used to selecting research projects according to the silk market demand. There is little consideration of whether the product design conforms to the need of the market. Thus their achievements are immature with poor market pertinence. These achievements are mainly lab results with no commercial effect, so it is hard to achieve technological transformation.

\subsection{To strengthen the enterprises' consciousness technological development and transformation of technological achievements.}

Low entry standard of silk industry has led to enterprises' ignorance of technological achievements. The enterprises pay more attention to short-term profit. Enterprises tend to invest in short-term projects and purse the quantity. Moreover, they are reluctant to invest in technological development with future benefits. Numerous enterprises have not formed a mature scientific research 
mechanism, while others do not invest in advanced achievements with strong market potential. At present, investment in technological development of silk industry accounts for $0.25 \%$ of sales profit. This is much lower than that of developed countries in textile industry, which is $5 \%$. Obviously, the overall independent innovative capability is weak.

\subsection{Current management system has restricted the technological achievement transformation efficiency.}

Laws and regulations related to transformation of technological achievements is not sound. The protection of intellectual property right is not powerful enough, and many achievements are used unpaid. Effective evaluation system of technological achievements has not been set up; the operating system which involves scientific research, development and industrialization has not taken shape; the technological market is lack of control and adjustment capability. The transformation of college technological achievements and the contribution of technology to economic construction are not clearly defined. Besides, no rational allocation of economic interests have led to low income of technical staffs and hence an impairment to their motives.

\section{Current model of technological achievement trans- formation in silk industry in China}

The model of technological achievement transformation refers to the operating mode in which the technological achievements are transformed into real productivity. Several main transformation models of silk industry are listed below.

\subsection{Government-dominated model}

Government-dominated model was once used in the period of planned economy. The transformation projects are included into the technological development plans of national and ministerial level by making use of various channels under the control of governments in different levels. However, technological achievements could not meet the actual requirements of markets, since the selection of projects is dominated by the government. As some results are lab achievements, they could not be applied to large-scale production activities. At the same time, this model lacks the driving force of commercial benefits. The motivation of enterprises and technical staffs can be easily dampened, resulting in insufficient funds and poor outcome of transformation.

\subsection{Industry-university-scientific research coopera- tion model}

It refers to the technological achievements transformation model involving colleges, technical and research institutes and enterprises. The three parties share the risks and benefits. It represents the long-term cooperation regarding technological achievements between suppliers and users. It is the colleges or technical research institutes' responsibility to make technical development and provide guidance to transform the technological achievements. All the conditions needed in large-scale production would be supplied by enterprises, so as to realize the industrialization of technical achievements in silk industry. The cooperation between enterprises, universities and scientific research institutes allows the scientific research institutes to bring its superiority in knowledge, personnel and technology into full play. The advantages of enterprises in funds, market, operation and management aspects can be maximized. The cooperation between the three parties shortens the cycle of technological achievement transformation.

\subsection{Technology transfer model}

Technology transfer is also called compensable transfer, in which universities or scientific research institutes transfer their technological achievements once and for all with partial or all franchise via technology market or other agencies to enterprises. Then the enterprises would be engaged in technological achievement transformation. The maturity of the technological achievements transferred in this way is usually high, with the suppliers and users technological achievements being different parties. The process is simple. It is a once-for-all transfer without taking any risks in product development.

\subsection{Entrepreneurship model led by talents}

Lack of funds from normal business channels can be attributed to the high risk, high input, high income and long cycle features of technological achievement transformation. Collaboration and innovation must be emphasized to promote technological achievement transformation. Only in this way could technology and economic development be combined tightly and their own functions be entirely fulfilled. Therefore, a complete innovation chain is formed. The entrepreneurship project led by talents in Suzhou Industrial Park in 2007 represents a new model for technological achievement transformation in silk industry. According to the stage of scientific and technological innovation projects, the listed projects will be supported from 12 aspects, including starting funds, equity investment (venture investment), loan provided by financial institutes, and complementary funds ${ }^{[2]}$.

\section{Innovation of technological achievement transfor- mation in silk industry}

To deal with the deep contradiction in China's technical achievement transformation in silk industry, the cooperation of seven parties including government, production sector, universities, scientific research institutes and financial institutes must be enhanced: specifically, to use administrative power of government; promote the collaborated innovation platform for expert consultation; improve technological development, information distribution, achievement transformation, industrial cultivation 
and financial services, with the innovation demand of enterprises as the market orientation, and the innovation of universities and scientific research institutes as the driving force.

\subsection{To build technological expert working committee in silk industry so as to provide macroscopic guidance}

The technological achievement transformation platform project in silk industry of Commerce Department was started in late 2012. Now the members of this working committee include experts from silk industry associations, universities, scientific research institutes and key enterprises. The working committee has an important expert working group in four key fields, which include modern processing and new material application technology, green ecological processing and resources and environmental technology, cultural creativity in silk industry and brand cultivation technology, informational management and integrated industrial development technology. The expert working committee and experts in certain fields provide support and services on technology-related policies, basic research, key technology and technological achievement transformation for varied technology activities in silk industry through cooperation with due division of labor.

\subsection{To look for top technological and educational tal- ents in silk industry and to upgrade industry technol- ogy}

The platform carries out a survey on silk talent development in domestic universities engaged in silk teaching and research, and in scientific research institutes, and some key enterprises. The survey consists of eight parts and is concerned with the past 5 years, including silk research, educational institutes, subject construction, projects, technological achievements and so on. The results of the survey are presented in Report on Technology, Education and Talent Development in Silk Industry. At the same time, relevant experts are invited to draw the technological development and upgrading roadmap in silk industry, so as to make clear the direction of future development of silk industry.

4.3. To strengthen the storage of technological achievements in silk industry and to enhance radiation effects of technology

The experts are organized to strengthen the research on projects, make analysis of achievements with the possibility of transformation, and bring transformable projects within a year into the list of technological transformation projects. The projects with high maturity and benefits are promoted with priority, and the projects that have lost the investment values and potential benefits are removed. As a result, the projects in storage are constantly changing. At present, the technological achievements that have been collected in four key fields are total nearly 160. The achievement publicity and promotion activities should be carried out in various regions based on thorough survey. These projects should be developed, linked up, transformed and stored one after another.

\subsection{To build information network platform for tech- nological transformation in silk industry}

The current technological achievement transformation model cannot meet with the demand of the society as social information amount is increasing by $40 \%$ every year. Therefore, it is urgent to explore for new transmission channels and ways of technological achievements. The technological achievement transformation platform in silk industry by Commerce Department has come up with a technology and information network, which is suited for economic environment with a networked structure. This network provides the market, technology and policy for universities and scientific research institutes, and information on disciplines, talents, projects, technological achievements, market demand, funds and even trade channels ${ }^{[3]}$ for enterprises. The aim is to promote positive interaction between the suppliers and users of technological achievements.

4.5. To promote the upgrading of the technological transformation of silk industry by coordinating different parties, namely, government, production sector, universities, scientific research institutes, financial institutes and so on

Government, enterprises, universities, scientific research institutes, technical agencies and financial institutes should fulfill their responsibilities and work together to provide services related to technical innovation of silk industry. These parties should make real-time communication with each other and optimize main resources and share the technological achievements through information network platform. The technical activities in silk industries should be guided towards the direction favourable to technological innovation and development of the silk industries. Therefore, the market orientation can be reinforced and the coordination of the project resources and clusters of silk industry can be realized. A promising future of technological innovation can be guaranteed by pushing forward the financial services construction supporting the transformation of technological achievements in silk industry.

\section{Conclusion}

The paper aimed to innovate the transfor-mation modes of scientific and technological achieve-ments in our silk industry, and increase the achievements transformation efficiency, expecting to promote our country developed into "silk power".

\section{References}

[1] Speech of Li Keqiang at the National Science and Technology Award Conference on January 10, 2014. 
[2]http://tech.sipac.gov.cn/webapply_szkj/default/InfoDet ial.aspx?infoid=11 acee0d-9cae-419b-82c1-ada8a4c3254c. [3]Wei Xinya \& Zhang Wujun. Study on innovative transformation model of college technological achievements in Beijing (J). Science and Technology Management Research, pp.238-240.2008(12). 